\title{
El «estado de suspensión fáctica» del Estado social autonómico
}

\author{
Abdelhamid Adnane \\ Profesor de Derecho Constitucional \\ Universidad Pablo de Olavide
}

\begin{abstract}
Sumario: 1. Notas introductorias.-2. Sobre el Estado Social Autonómico.-3. Estado Social Autonómico y Responsabilidad del Estado por incumplimiento por parte de las Comunidades Autónomas de los compromisos internacionales. 3.1. Excurso sobre los derechos sociales en la jurisprudencia internacional.- 4. Estado Social Autonómico y redefinición del margen de maniobra de las Comunidades autónomas a la luz de la STC 134/2011.-5. Notas finales.
\end{abstract}

\section{NOTAS INTRODUCTORIAS}

$\mathrm{Si}$ a nadie puede ocultársele que una de las características principales del Estado, como forma de organización política del poder, es su soberanía tanto ad intra como ad extra, tampoco requiere mucho esfuerzo percatarse de que uno de los retos a los que esta nueva forma de organización política se enfrenta hoy por hoy es la aparición en el ámbito privado de nuevos centros de poder de naturaleza principalmente económica cuya capacidad de presión y de pilotaje de las decisiones políticas va in creciendo en el contexto de la globalización que pretende imponer, de facto, el carácter materialmente político del capital.

Dicho poderes denominados como «salvajes» ${ }^{1}$, por estar desregulados, que huyen de todas la técnicas tendentes a limitar el poder en aras de fortalecer el estatus de ciudadano, se afanan en evidenciar el carácter «inservible» del viejo Estado nacional cuyo origen se remonta a la paz de Westfalia, y en promover la disposición de elementos tanto fácticos como jurídicos para convertir en realidad aquello que se viene definiendo como la aldea global ${ }^{2}$.

${ }^{1}$ Cfr. Ferrajoli, L., «Más allá de la soberanía y la ciudadanía: un constitucionalismo global», Isonomía, núm. 9, México, octubre 1998, págs. 173-186.

${ }^{2}$ Al respecto escribe el profesor Ruíz PéREz que «al producirse el desmantelamiento del sistema comunista y, con ello, haber desaparecido del horizonte político el clima de la guerra fría, aparecerá la idea de que los esquemas conceptuales del viejo Derecho Constitucional, nacido en el marco de una realidad social harto distinta, pierde todo su significado y sentido. Siendo así lo que se nos propondrá es la sustitución del, según dicen, acabado modelo por uno nuevo, que sea capaz de organizar la convivencia en una sociedad única para todo el orbe. El Estado nacional, afirmarán deberá ser sustituido, no ya por aquel "Estado continental" que, aunque comenzado a defender en los primeros años del siglo XX, alcanzaría su máxima expresión en la Europa de la segunda posguerra, y que, en cualquier caso, se presenta ya como un modelo estrecho y raquítico para las necesidades contemporáneas, sino por la aldea global». Cfr. Ruíz Pérez, J., «¿La Constitución en 
Uno de ellos, traído a colación por su patente importancia es el libre flujo de capitales que dio lugar a lo que algunos economistas han llamado «un senado virtual» ${ }^{3}$, eso es un centro de poder no estatal integrado por instituciones financieras, en condiciones de imponer su propia política mediante la amenaza de evasión ${ }^{4}$ de capitales que podría acarrear «tipos de interés más altos, ralentización económica, recortes presupuestarios en la sanidad y en la educación, etc., o tal vez una recesión o un colapso total». ${ }^{5}$.

El Estado español se encuentra sumergido en esta lógica imperante y de ahí que sus políticas estén fuertemente condicionadas por los imperativos de un mercado que reclama para sí la supremacía propia del poder constituyente en tanto condiciona el diseño de las políticas sociales y económicas desplegables a nivel estatal, y predetermina aquellas que, en virtud del reparto competencial iniciado por la Constitución y desarrollado por los Estatutos de Autonomía, afectan a los ámbitos regionales ${ }^{6}$.

crisis? El Estado Constitucional Democrático y Social en los tiempos del neoliberalismo tecnocrático» en Revista de Estudios Políticos, núm. 20, 2003, págs. 127-171.

${ }^{3}$ Cfr. Terol Becerra, M. J., «Globalización versus Universalización constitucional en el Mediterráneo. Propuesta metodológica para un análisis de la diversidad» en Revista de derecho político, $\mathrm{N}^{\circ}$ 60, 2004, pág. 77.

${ }^{4}$ Como señala Pisarello, el episodio decisivo fue el fracaso del último proyecto reformista serio en un país europeo: el de la coalición social-comunista francesa a principios de los 80. Sus intentos de introducir cambios estructurales y la nacionalización de algunas entidades bancarias obtuvieron como respuesta huidas de capitales y presiones de los mercados financieros internacionales. El fracaso sirvió de «aviso para navegantes». EsTÉVEZ ARÁUJO, J. A., «Globalización neoliberal y democracia» en http://firgoa.usc.es/drupal/ node/50499, última consulta el 07 de diciembre de 2012.

${ }^{5}$ Cfr. Chomsky, N., «Los mercados y la sustancia de la sociedad» en AA.VV., Los límites de la globalización, Ariel, Barcelona, 2002, pág. 33.Citado por Terol BECERRA, M. J., «Globalización versus Universalización constitucional en el Mediterráneo. Propuesta metodológica para un análisis de la diversidad» en Revista de derecho político, $\mathrm{N}^{\circ} 60, \mathrm{Ob}$. Cit., Pág. 77. En el mismo sentido apunta Habermas que «el capital libre y sin trabas (...) puede amenazar con ejercer su opción de salida cada vez que un gobierno pone limitaciones onerosas a las condiciones para la inversión interna con la intención de salvaguardar sus niveles de protección social». Cfr. Habermas, J., «El valle de lágrimas de la globalización» en Claves de razón práctica, núm. 109, pág. 6, citado por por TEROL BECERRA, M. J., «Globalización versus Universalización constitucional en el Mediterráneo. Propuesta metodológica para un análisis de la diversidad» en Revista de derecho político, $\mathrm{N}^{\circ} 60, \mathrm{Ob}$. Cit., pág. 77.

6 En este sentido apunta el profesor PéREz CALVO «El Estado, autosuficiente jurídicamente en otro tiempo, manifiesta hoy su incapacidad para hacer frente a nuevas situaciones de las que depende nuestra vida personal y social. Y ese mismo Estado, que había logrado un equilibrio relativamente estable en su estructura interna, en las relaciones entre el Gobierno y el Parlamento, y entre la federación y las entidades federadas, en la nueva situación necesita recomponer unos equilibrios internos nuevos». Cfr. PÉrez CAlvo, A., «Estado autonómico, Unión Europea y mundialización» en http://www.falternativas.org/ laboratorio/documentos/documentos-de-trabajo/estado-autonomico-union-europea-ymundializacion, última consulta el 07 de diciembre de 2012, pág. 5. 
Un breve repaso de la batería de reformas legislativas llevadas a cabo en los últimos años, justificadas todas por la crisis económica ${ }^{7}$ y orientadas a paliar sus efectos, y rematadas por la nueva redacción del artículo 135 de la Constitución, dibujan un horizonte sombrío para el Estado Social ${ }^{8}$, cuyos principales realizadores desde la puesta en marcha del Estado autonómico, han sido las Comunidades Autónomas ${ }^{9}$. Éstas, a pesar de que las últimas reformas estatutarias han permitido la ampliación de su techo competencial, principalmente en materia prestacional, ven el alcance de sus competencias determinado por una necesaria lectura combinada entre sus posibilidades de acción integrantes del bloque de constitucionalidad y la escasez de recursos que da origen a las normas tendentes a la racionalización del gasto tanto del poder central como de los autonómicos, y a su subordinación a la política económica general del gobierno central que, a su vez, obedece al cumplimiento de obligaciones internacionales y a imperativos de los mercados financieros.

La presente reflexión se propone repasar de modo genérico los elementos jurídicos que contribuyen a desvirtuar la potencialidad social del Estado español a través, principalmente, de la limitación del alcance prestacional

${ }^{7}$ Afirma el profesor Jordano Fraga que «La crisis de deuda ha generado políticas de austeridad y contención del gasto que conllevan el incremento de la presión fiscal (subidas en Europa del IVA en un rango de tipo general de nuestro 18\% al $24 \%$-en España del 17 al 21\% con efectos de septiembre de 2012-) o bien mediante la reintroducción de impuestos (impuesto sobre el patrimonio, impuesto sobre sucesiones allí donde fue suprimido, introducción del impuesto sobre la primera casa (IMU) que incluyó el Ejecutivo en el plan de ajustes de 30.000 millones del Ejecutivo de MONTI)», Jordano Fraga, J., " El Derecho administrativo de la crisis» en XIX Congreso italo español de profesores de Derecho Administrativo, Madrid 18, 19 y 20 de octubre de 2012. http:/uspceu.es/pages/ congresos/italo-espanol/ docs/ponencias/J.\%20JORDANO.\%20EL\%20DERECHO\%20 ADMINISTRATIVO\%20DE\%20LA\%20CRISIS.pdf. Última consulta el 29/10/2012.

8 Citamos a título de ejemplo las siguientes normas: Real Decreto-ley 4/2010, de 26 de marzo, de racionalización del gasto farmacéutico con cargo al Sistema Nacional de Salud, BOE (Boletín Oficial del Estado), de 27 de marzo de 2010, núm 75; Real Decreto-ley $20 / 2011$, de 30 de diciembre, de medidas urgentes en materia presupuestaria, tributaria y financiera para la corrección del déficit público, $B O E$, de 31 de diciembre de 2011, núm 315; Ley Orgánica 2/2012, de 27 de abril, de Estabilidad Presupuestaria y Sostenibilidad Financiera, $B O E$, de 30 de abril de 2012, núm 103; Real Decreto-ley 20/2012, de 13 de julio, de medidas para garantizar la estabilidad presupuestaria y de fomento de la competitividad, $B O E$, de 14 de julio de 2012, núm 168; Real Decreto-ley 14/2012, de 20 de abril, de medidas urgentes de racionalización del gasto público en el ámbito educativo, $B O E$, de 21 de abril de 2012, núm 96; Real Decreto-ley 16/2012, de 20 de abril, de medidas urgentes para garantizar la sostenibilidad del Sistema Nacional de Salud y mejorar la calidad y seguridad de sus prestaciones, $B O E$, de 24 de abril de 2012, núm 98; Ley 3/2012, de 6 de julio, de medidas urgentes para la reforma del mercado laboral, $B O E$, de 7 de julio de 2012, núm 162.

${ }^{9}$ Véase a este respecto el libro del profesor Terol Becerra, M. J., Del bienestar en la Constitución Española y de su implementación (1978-2011), Tirant lo Blanch, Valencia, 2011. 
del bloque competencial de las Comunidades Autónomas. Limitación que obedece tanto a que es el Estado quien debe responder de los compromisos contraídos a nivel internacional como a que la definición de la política económica general le corresponde al Estado ex artículo 149.1.13, competencia cuyo alcance obedece en gran medida a la lógica de la lexmercatoria.

\section{SOBRE EL ESTADO SOCIAL AUTONÓMICO}

Justo después de la aprobación de la Constitución española de 1978 empiezan a oírse manifestaciones políticas portadoras de mensajes a favor de la necesaria concreción del programa social recogido en la norma fundamental. Concreción que sólo parcialmente le incumbe al poder central ya que en virtud del marco de la posible auto-atribución de competencias por parte de las Comunidades autónomas una vez constituidas, éstas podrían desplegar sus políticas a favor de la construcción del Estado del bienestar al que el constituyente se había comprometido.

El reconocimiento constitucional de la autonomía política y la precisión de las competencias en los Estatutos son las premisas necesarias para la edificación del Estado Social autonómico español. El respeto a la competencia del artículo 149.1.1 es compatible con la capacidad de las Comunidades Autónomas de llevar a cabo políticas sociales propias diferenciadas en las materias de la competencia respectiva y que, al hacerlo, determinan una diversidad de regímenes jurídicos en cada una de ellas con los consiguientes efectos sobre los ciudadanos de cada territorio autonómico.

Dejando aparte las previsiones constitucionales establecientes de los cimientos para la construcción del referido edificio, gran parte de las Comunidades Autónomas han hecho suya, en sus primeras actas fundacionales, esta labor incluyendo en sus respectivas normas institucionales básicas disposiciones estatutarias de marcado contenido social ${ }^{10}$, comprometiéndose con ello a hacer de la consecución del bienestar un objetivo primordial de toda su política.

Este compromiso se ha visto renovado y, si cabe, ampliado en las últimas reformas al configurar derechos sociales de rango estatutario, despojados posteriormente de tal carácter por la Sentencia del Tribunal Constitucional 31/2010. Ello no obstante su compromiso con las políticas sociales no ha mermado, pues buena prueba de ello es la actividad legislativa desplegada por estos entes territoriales tendente a satisfacer ciertas necesidades sociales que resultarían sacrificadas si se hubieran dejado al esfuerzo personal del ciudadano.

Cabe subrayar que la actividad legislativa de algunas Comunidades $\mathrm{Au}-$ tónomas en materia de derechos llega a cuadriplicar (por ejemplo, la de $\mathrm{Ca}$ -

${ }^{10}$ Cfr. en este sentido los artículos 12.3.4 y 12.3.5 de la Ley Orgánica 6/1981, de 30 de diciembre, de Estatuto de Autonomía para Andalucía, BOE, de 11 de enero de 1982, núm 9 . 
taluña respecto de La Rioja o Asturias) o a duplicar la de otras (por ejemplo, Aragón respecto de la Comunidad de Madrid o de Extremadura), a pesar de haber mantenido históricamente todas ellas similares competencias. Cierto es también que no todos los nuevos Estatutos han incorporado catálogos exhaustivos de derechos, deberes y principios rectores. Pero no es menos cierto también que todas las Comunidades Autónomas sin excepción han legislado, y en general profusamente, sobre derechos de muy distinta naturaleza y en muy distintos ámbitos: familia, igualdad, educación, trabajo, salud, cultura, servicios sociales, derechos lingüísticos y culturales, vivienda, consumidores, buena administración, o medio ambiente ${ }^{11}$.

Si ello no ha sido consecuencia directa de los declarados no derechos por la mencionada sentencia, puede afirmarse que no faltan asideros estatutarios para tal actuación. De hecho, reiteradas son las referencias a la calidad de vida y al bienestar, «indiciarias de ese tratamiento detenido que en ellos reciben, bien como principios rectores de las políticas públicas autonómicas, en general, o de las políticas económica, tributaria, de mayores, de menores o de género, por ejemplo, en particular; bien como objetivos básicos de la Comunidad Autónoma, con la invocación, a veces, del Estado de bienestar como telón de fondo, cuando no recibe el bienestar social la consideración de competencia exclusiva ${ }^{12}$. Ello puede comprobarse, por ejemplo, en el preámbulo de la Ley Orgánica 1/2006, de 10 de abril, de Reforma de la Ley Orgánica 5/1982, de 1 de julio, de Estatuto de Autonomía de la Comunidad Valenciana; el Preámbulo y los artículos 17, 40, 41.5, 42, 45.2, 53.2, 203.6 y 206.3 de la Ley Orgánica 6/2006, de 19 de julio, de reforma del Estatuto de Autonomía de Cataluña; los artículos 16.3, 30.15, 123.2 y 124.2 de la Ley Orgánica 1/2007, de 28 de febrero, de reforma del Estatuto de Autonomía de las Illes Balears; El Preámbulo y los artículos 10.3.6 $6^{\circ} 10.3 .7^{\circ}, 10.3 .8^{\circ}$, $\left.\left.10.3 .14^{\mathrm{o}}, 18.1,19,37.1 .4^{\mathrm{o}}, 48.3^{\mathrm{a}}\right) .162 .2,175.2 . c\right), 179.3,201$ y 202 de la Ley Orgánica 2/2007, de 19 de marzo, de reforma del Estatuto de Autonomía para Andalucía; los artículos 12.2, 23.2.a), 24.a), 99.3 y 107.2 de la Ley Orgánica 5/2007, de 20 de abril, de reforma del Estatuto de Autonomía de Aragón, y el Preámbulo y los artículos 13.6, 16.2 y 78.1 de la Ley Orgánica 14/2007, de 30 de noviembre, de reforma del Estatuto de Autonomía de Castilla y León ${ }^{13}$.

Suscribimos, tras este breve repaso, la afirmación de BARCELó I SERRAMALERA de que no es mal balance el que resulta de la actividad legislativa

${ }^{11}$ Cfr. Barceló i Serramalera, M., «La Contribución de las Comunidades Autónomas en el reconocimiento y regulación de los derechos sociales» en Lex Social-Revista de los Derechos Sociales, ${ }^{\circ}$ 1, julio 2011, Pág. 2, http://www.upo.es/revistas/index.php/ lex social/article/view/236, última consulta el 07 de diciembre de 2012.

${ }^{12}$ Terol Becerra, M. J., "Treinta años de desarrollo constitucional y legislativo de los derechos sociales: Derechos ciudadanos y principios rectores» en Derechos sociales y principios rectores. Actas del IX Congreso de la Asociación de Constitucionalistas de España.

13 Ídem. 
autonómica en el ámbito de los derechos sociales: se ha dado forma de verdaderos derechos subjetivos a nivel autonómico a mandatos constitucionales de promoción y protección dirigidos a los poderes públicos allí dónde han existido competencias para ello; se han creado verdaderas estructuras serviciales en educación, sanidad y servicios sociales; y se han desplegado políticas tuitivas en beneficio de categorías sociales desprotegidas o discriminadas en forma de derechos. Todo ello reforzado con la posibilidad de tutela en sede jurisdiccional ${ }^{14}$.

Si este es el estado actual del Estado Social autonómico, ¿de qué margen de maniobra podrá disponer el legislador autonómico para seguir llevando a cabo su labor social teniendo en cuenta las llamadas a la austeridad lanzadas desde las instancias europeas recordando los compromisos contraídos por los Estados miembros?

\section{ESTADO SOCIAL AUTONÓMICO Y RESPONSABILIDAD DEL ESTADO POR INCUMPLIMIENTO POR PARTE DE LAS CO- MUNIDADES AUTÓNOMAS DE LOS COMPROMISOS INTER- NACIONALES}

En tiempos de dificultades económicas patentes se impone por vía normativa, desde las instancias gubernativas centrales, la necesidad de operar una racionalización del gasto público y de llevar a cabo políticas de austeridad en aras de reducir el déficit del que se aqueja la economía nacional. Dicho esfuerzo está llamado a afectar ineludiblemente a la faceta prestacional del Estado, desplegada en gran parte por las Comunidades Autónomas tal como queda señalado en el apartado anterior. Ello, como es de todos conocido, responde a las exigencias de una política económica trazada desde instancias europeas, en respuesta a las exigencias de los mercados financieros, cuyo eslogan principal es la necesidad de saneamiento de las cuentas públicas operando amplios recortes presupuestarios como una salida posible de la crisis económica.

Dichas políticas de austeridad afectan sobremanera a las políticas autonómicas tendentes a garantizar el llamado bienestar material de los ciudadanos, y repercuten en sentido restrictivo sobre su autonomía presupuestaria que ha de ser acorde con las directrices del poder central que, muchas veces, no son más que la traducción de su compromiso europeo con el Pacto de Estabilidad y Crecimiento ${ }^{15}$ cuyo fundamento normativo se encuentra en los

${ }^{14}$ Cfr. Barceló i Serramalera, M., «La Contribución de las Comunidades Autónomas en el reconocimiento y regulación de los derechos sociales» en Lex Social - Revista de los Derechos Sociales, nº 1, Ob. Cit., págs. 31-32.

${ }^{15}$ La resolución del Consejo Europeo de 17 de junio de 1997 sobre el Pacto de estabilidad y crecimiento y los Reglamentos (CE) núm. 1466/1997, del Consejo, de 7 de julio -relativo al reforzamiento de la supervisión de las situaciones presupuestarias y a la supervisión y coordinación de las políticas económicas- y 1467/1997, del Consejo, de 7 de julio -relativo a la aceleración y clarificación del procedimiento de déficit excesivo- 
artículos 99 y 104 del Tratado de la Unión Europea (actualmente, artículos 121 y 126 del Tratado de Funcionamiento de la Unión Europea).

Recuérdese que el Derecho Internacional, aun dejando cierta libertad para los Estados, les exige un cabal cumplimiento de las obligaciones internacionales, y rechaza la posibilidad de que pueda invocarse las normas internas para justificar el incumplimiento de tales compromisos. Consecuencia lógica de ello es que la responsabilidad de un posible incumplimiento se imputa al Estado, sea cual sea el órgano o el nivel dónde se haya producido.

La misma lógica impera en el ámbito europeo bajo el principio de indiferencia de tal modo que España responde de las infracciones comunitarias imputables a cualquiera de sus órganos, sea del nivel que sea, incluyendo, por supuesto, las infracciones cometidas por sus entes regionales ${ }^{16}$. El procedimiento habilitado para interponer el recurso de incumplimiento viene establecido por los artículos 226 y 228 del Tratado CE. De no solucionarse el incumplimiento de la Comunidad Autónoma en un plazo razonable, el Estado español corre el riesgo de que se inicien nuevos procesos de incumplimiento del Derecho comunitario con vistas a imponerle una sanción económica a tanto alzado y/o una multa coercitiva (artículo 228 del Tratado

tienen como finalidad concretar el alcance del llamado Pacto de estabilidad y crecimiento. Dicho Pacto, según la exposición de motivos del Reglamento CE núm. 1466/1997, «se basa en el objetivo de finanzas públicas saneadas como medio de reforzar las condiciones para la estabilidad de los precios y para un crecimiento sólido y sostenido que conduzca a la creación de empleo», de manera que «se formulan orientaciones políticas firmes ... para ajustarse al objetivo a medio plazo de situaciones presupuestarias próximas al equilibrio o de superávit, al que todos los Estados se han comprometido, y para tomar las medidas presupuestarias correctoras que estimen necesarias para alcanzar los objetivos fijados en sus programas de estabilidad y convergencia», y se procede a "completar el procedimiento de supervisión multilateral previsto en los apartados 3 y 4 del art. 103». En este contexto, la exposición de motivos del Reglamento CE núm. 1467/1997 señala que «es necesario acelerar y clarificar el procedimiento del déficit excesivo contemplado en el art. $104 \mathrm{C}$ del Tratado con el fin de evitar que se produzcan déficit excesivos de las administraciones públicas $\mathrm{y}$, en caso de que se produjeran, con el fin de propiciar su rápida corrección», por lo que «es necesario establecer plazos para la aplicación del procedimiento». Vid. STC 134/2011, de 20 de julio de 2011, FJ. 5.

${ }^{16}$ Cfr. Cienfuegos Mateo, M., Comunidades Autónomas, Tribunales de la Unión Europea y responsabilidad por el incumplimiento autonómico del Derecho comunitario. Reflexiones a partir de la práctica reciente, Pág. 16. Visto en dialnet.unirioja.es/descarga/ articulo/2478816.pdf. Última consulta el 07 de diciembre de 2012. En este sentido se pronuncia el TJCE su Sentencia de 25 de mayo de 1982 (Comisión c. Países Bajos, 9781), «Es verdad que cada Estado miembro es libre de distribuir como juzgue oportuno las competencias en el plano interno y de adaptar una directiva por medio de medidas acordadas por autoridades regionales o locales. Esto no podría, sin embargo, dispensarle de la obligación de traducir las disposiciones de la directiva en disposiciones internas que tengan carácter obligatorio». 
$\mathrm{CE})^{17}$, de lo que extrae el Tribunal Constitucional la facultad del Estado para establecer mecanismos de coordinación y control que «permitan evitar las irregularidades o las carencias [autonómicas] en el cumplimiento de la normativa comunitaria» ${ }^{18}$.

En casos de «normalidad económica» la responsabilidad de los entes autonómicos por incumplimiento del Derecho comunitario puede dar lugar a dos tipos de situaciones ${ }^{19}$ : por un lado, a una reclamación de responsabilidad patrimonial de las Comunidades Autónomas; por otro lado, a la repercusión en las Autonomías responsables de la infracción del Derecho comunitario del importe de las sanciones económicas impuestas a España por este hecho ${ }^{20}$.

Sin embargo, con la actual crisis financiera que se ha traducido en un elevado déficit presupuestario en todas las Administraciones Públicas españolas, lo cual ha precipitado reformas que limitan cuantitativamente el crecimiento anual de los gastos en que puede incurrir cada entidad pública, el cumplimiento de la normativa europea supone una «suspensión fáctica» del contenido prestacional del bloque competencial anudado a la autonomía política de las Comunidades Autónomas. De ahí que un ejercicio constitucionalmente legítimo de las competencias pueda dar lugar al incumplimiento de las normas europeas sobre el déficit con la posible imposición de una sanción al ente incumplidor. A tener en cuenta las reiteradas declaraciones del Ministro de Hacienda que hacen valer los medios de acción de naturaleza preventiva como la posible intervención de la Comunidad Autónoma, el futuro del Estado social autonómico, cuanto menos a corto plazo, se presenta poco halagüeño.

Antes de cerrar este epígrafe una observación se impone. En España, la falta de ratificación de la Carta Social revisada viene a ser suplida por la ratificación del Pacto Facultativo al Protocolo de derechos económicos, sociales y culturales, que tiene el mismo valor, jurídicamente hablando, que cualquier Tratado celebrado a nivel europeo ${ }^{21}$. De ahí que su cumplimiento le corresponda tanto al Estado central como a las entidades regionales, y que la satisfacción de los derechos sociales por vía de la labor prestacional se configure

17 Cienfuegos Mateo, M., Comunidades Autónomas, Tribunales de la Unión Europea y responsabilidad por el incumplimiento autonómico del Derecho comunitario. Reflexiones a partir de la práctica reciente, Ob. Cit., Pág. 19.

18 Vid. STC 148/1999, de 2 de julio, FJ 8.

${ }^{19}$ Cfr. Cienfuegos Mateo, M., Comunidades Autónomas, Tribunales de la Unión Europea y responsabilidad por el incumplimiento autonómico del Derecho comunitario. Reflexiones a partir de la práctica reciente, Ob. Cit., Pág. 37.

${ }^{20}$ En su Sentencia del 96/2002, de 25 de abril de 2002 (FJ. 10), el Tribunal Constitucional declaró que la responsabilidad del Estado frente a la Unión Europea por incumplimientos autonómicos del Derecho comunitario no «le impide repercutir ad intra, en las Administraciones públicas autonómicas competentes, la responsabilidad que en cada caso proceda».

${ }^{21}$ Vid Artículo 96.1 CE. 
como un deber cuyo incumplimiento ha de dar lugar a una sanción. Pues, la ratificación del referido Pacto obliga tanto al Estado como a las Comunidades Autónomas. $\mathrm{O}$ acaso ¿puede tacharse en este caso de incumplimiento de la norma europea un cumplimiento de otra internacional (PIDESC en este caso), sino por los poderes políticos cuanto menos por el poder judicial en su labor de garante de los derechos, integrando el contenido de la jurisprudencia internacional sobre la materia en los derechos previstos por el ordenamiento español?

\subsection{Excurso sobre los derechos sociales en la jurisprudencia internacional}

La idea de crear un pedestal social en favor de los necesitados, a fin de protegerles de la indigencia se inscribe en una lógica integradora del Estado social. Se trata de atribuir a cada uno un mínimo que le permita hacer frente a situaciones de urgencia. De ahí la reclamación de un derecho fundamental a un mínimo vital o a medios de existencia, denominados también como derechos a condiciones mínimas de existencia.

Concebido a mínima, hace referencia al derecho a la subsistencia que comprende el derecho a los alimentos, a un techo, a la vestimenta y a garantizar la asistencia sanitaria ${ }^{22,23}$.

Sin embargo, en su concepción a maxima, considerando el individuo como ser social, necesitado no sólo de alimentos sino también de relaciones sociales para su realización personal, el derecho a condiciones mínimas de existencia responde a la necesidad de garantizar un nivel de vida decente. Se trata, pues, de disponer las condiciones materiales necesarias para que todo individuo pueda recobrar su libertad y acceder a los otros derechos fundamentales ${ }^{24}$ debido a que la pobreza se equipara a la denegación de un

${ }_{22}$ Así, el Tribunal Federal Suizo ha considerado, en una importante decisión de 1995, que la satisfacción de las necesidades básicas de la persona humana, tales como el alimento, la vestimenta y la vivienda representa la condición misma de la existencia humana y del desarrollo de la persona.

${ }^{23}$ En su decisión de marzo de 1996, la Comisión Africana de los derechos del hombre y de los pueblos evoca un «estándar mínimo de salud», que comprende el acceso al agua potable y a la electricidad así que a los medicamentos de base. CADHP, mars 1996, Communications 25/89, 47/90, 56/91, 100/93, Free Legal Assistance Group, Lawyers Committee for Human Rights, Union Interafricaine des Droits de l'Homme, Les Témoins de Jehovah c. Zaire.

${ }^{24}$ En su recomendación del 27 de octubre de 2001, la Comisión africana «descubre» los derechos a la vivienda y a la alimentación, no inscritos expresamente en la Carta africana. Les concibe, sobre todo como inexcusablemente unidos. Tal proceder permite concebir el derecho a condiciones mínimas de existencia en tanto que derecho social, es decir en tanto que condición de acceso a los demás derechos fundamentales. Bastante explícito al respecto, el Tribunal Federal suizo recuerda en 1995 que este derecho, destinado a evitar «toutétat de mendicité indigne de la conditionhumaine» representa la condición para el ejercicio de todos los demás derechos fundamentales y no puede ser limitado salvo en casos excepcionales. 
conjunto de derechos. Es, de hecho, incontestable que «pour être en mesure d'invoquer son droit à l'éducation, par exemple, mais également sa liberté d'expression, un individu doit avant tout manger à sa faim» ${ }^{25}$.

La efectividad mínima de este derecho tiene ya apoyo en la jurisprudencia comparada. De hecho, la justicia constitucional alemana, a propósito de una ley relativa a las pensiones de huérfanos minusválidos, ha declarado que la asistencia a los necesitados forma parte de las «obligaciones evidentes» del Estado social ${ }^{26}$. Ahora bien, éste implica la obligación de asistencia, es decir una obligación jurídica objetiva del Estado de garantizar a la población una «protección social mínima» ${ }^{27}$. En otra sentencia el mismo Tribunal apela a la dignidad y no al concepto de «Estado social» de rango constitucional, para derivar de ello una lista de derechos sociales no mencionados en la norma fundamental alemana.

En la misma línea de garantía de los derechos sociales, haciendo uso del principio de interconexión de los derechos, y permitiendo enriquecer su competencia rationae materiae, la Corte Europea de los derechos humanos, opera mediante una estrategia de ampliación de los derechos alegando las prolongaciones socio-económicas de los derechos civiles y, de ahí, impone al Estado ciertas acciones positivas. Esta manera de abordar los derechos viene ilustrada en su sentencia emitida a propósito del contencioso relativo a la situación causada por los gitanos en la Europa del este al estimar que «les conditions dans lesquelles les requérants ont vécu ces dix dernières années, notamment la promiscuité et l'insalubrité et leurs effets délétères sur la santé et le bien-être des requérants, associées à la durée pendant laquelle ces derniers ont été contraints de vivre ainsi et à l'attitude générale des autorités, ont nécessairement dû leur causer des souffrances psychologiques considérables et, partant, porter atteinte à leur dignité humaine et susciter chez eux des sentiments d'humiliation et d'avilissement. $\rangle^{28}{ }^{29}$.

El Tribunal Constitucional Federal alemán subraya a su vez, tras un recurso interpuesto por un paciente, afectado de una enfermedad extremamente grave, reclamando el reintegro de los gastos médicos no cubiertos, la importancia del principio constitucional de Estado social y de los derechos fundamentales a la vida y a la libertad, y ha considerado que la denegación del reintegro de los gastos médicos elegidos por el paciente para tratar su

${ }^{25}$ Fercot, C., «Le juge et le droit au minimum. les ambiguïtés du droit à des conditions minimales d'existence en droit comparé», en Droits des pauvres, pauvres droits? Recherches sur la justiciabilité des droits sociaux, Section 2, pág.. 222.

26 Ídem.

27 Ídem.

${ }^{28}$ Roman D., «Les droits civils au renfort des droits sociaux: l'interchangeabilité des droits fondamentaux dans le discours judiciaire» en Droits des pauvres, pauvres droits? Recherches sur la justiciabilité des droits sociaux, Ob. Cit., pág. 310.

${ }^{29}$ Para más información, véase Sempere NAvarro, A. V., (Dir.), Prontuario de Jurisprudencia social del Tribunal Europeo de Derechos Humanos, Aranzadi, Navarra, 2009. 
enfermedad considerada como extremamente grave e incluso mortal y para la cual ningún medio de tratamiento convencional era disponible, viola dichos principios $^{30}$.

La mencionada jurisprudencia, entre otras, coadyuvó en la realización de la igualdad materialmente concebida e impuso a los poderes políticos obligaciones cuyo desconocimiento u omisión podría ser, llegado el caso, sancionado en sede judicial. Inferencia lógica de ello es que el poder político estatal ha de operar una ponderación entre las obligaciones que imponen un equilibrio presupuestario, con lo que de ellas deriva de ajustes en la política de gastos, y los compromisos con los derechos sociales derivados de los Tratados ratificados y de la jurisprudencia que de los mismos realizan los órganos competentes.

\section{ESTADO SOCIAL AUTONÓMICO Y REDEFINICIÓN DEL MARGEN DE MANIOBRA DE LAS COMUNIDADES AUTÓNO- MAS A LAS LUZ DE LA STC 134/2011}

A la limitación, arriba mencionada, derivada de una posible sanción por incumplimiento se añade otra, avalada por el Alto Tribunal, referida a la competencia estatal de dirección de la actividad económica general con base en el artículo 149.1.13 CE.

Resta, pues, comprobar las posibilidades de acción de las que pueden disponer las Comunidades Autónomas a la luz de la interpretación realizada por el Tribunal Constitucional en la STC 134/2011 del concepto de autonomía política y del alcance de la autonomía financiera constitucionalmente garantizada. El repaso de ciertos pasajes de esta sentencia nos informa sobre la subordinación del Estado social autonómico a las orientaciones de política económica general cuyo artífice es el Estado.

De hecho la STC 134/2011, de 20 de julio, que resuelve el recurso de inconstitucionalidad promovido contra la Ley 18/2011, de 12 de diciembre, General de Estabilidad Presupuestaria y contra la Ley Orgánica 5/2011, de 13 de diciembre, complementaria de la Ley General de Estabilidad Presupuestaria elabora un corpus jurisprudencial que viene a redimensionar la autonomía política de las Comunidades Autónomas y, en lo que respecta a los derechos sociales para cuya realización se hace preciso cierto esfuerzo económico, a legitimar una «suspensión» del proceso de construcción del Estado Social.

La referida sentencia presenta un gran interés para el tema que nos ocupa ya que hace referencia al significado y al alcance del principio de autonomía política y financiera de las Comunidades Autónomas en relación con las competencias estatales. En efecto, tras subrayar que la estabilidad presupuestaria se configura como una orientación de política económica general que el Estado puede dictar ex art. 149.1.13, define la autonomía política y

${ }^{30}$ GRÜNDLER, T., «Le droit à la protection de la santé» en Droits des pauvres, pauvres droits ? Recherches sur la justiciabilité des droits sociaux, Ob. Cit., pág. 210. 
financiera de las Comunidades Autónomas establecida en los artículos 2 y 137 de la Constitución como «la capacidad de autogobierno, que se manifiesta, sobre todo, en la capacidad para elaborar sus propias políticas públicas en las materias de su competencia» y que «ofrece una vertiente económica importantísima $\rangle^{31}$. Añade el Alto Tribunal, con remisión a su jurisprudencia anterior $^{32}$ que ello «implica la plena disponibilidad de sus ingresos sin condicionamientos indebidos y en toda su extensión, para poder ejercer las competencias propias $y$, en especial, las que se configuran como exclusivas $\rangle^{33}$, sin que por ello dicha libertad tenga carácter absoluto. Lo que en definitiva reconoce la constitucionalidad del establecimiento de controles, incluso específicos «para asegurar la coordinación de la política autonómica en un determinado sector económico con programación, a nivel nacional» ${ }^{34}$.

Teniendo en cuenta este planteamiento, el Tribunal Constitucional considera que la estabilidad presupuestaria entraría dentro de este concepto de control que se justifica a partir del artículo 149.1.13 de la Constitución, lo que habilita al gobierno a establecer límites presupuestarios en materias concretas porque la limitación de gasto impuesta a las Administraciones públicas «encuentra su apoyo en la competencia estatal de dirección de la actividad económica general (ex art. 149.1.13) y su establecimiento está encaminado a la consecución de la estabilidad económica y la gradual recuperación del equilibrio presupuestario ${ }^{35}$. Con base en este razonamiento, el Gobierno puede tomar las medidas que considere necesarias en aras de, por ejemplo, limitar el déficit de las Comunidades Autónomas y controlar los gastos sociales de los gobiernos autonómicos.

Ahondando en el carácter no absoluto de la autonomía política y financiera de las Comunidades Autónomas, fundamenta el Tribunal Constitucional la imposición de topes máximos de gasto por parte del Estado en «el límite a la autonomía financiera que establece el principio de coordinación con la Hacienda estatal del art. 156.1 CE, con el alcance previsto en el art. 2.1 b) LOFCA, el cual exige a las Comunidades Autónomas la acomodación de su actividad financiera a las medidas oportunas que adopte el Estado tendentes a conseguir la estabilidad económica interna y externa, toda vez que a él corresponde la responsabilidad de garantizar el equilibrio económico general (SSTC 171/1996, FJ 2; 103/1997, FJ 1)» ${ }^{36}$.

En la misma línea se apunta por parte del Alto Tribunal que, en este marco multilateral de coordinación y cooperación propio de la materia «financiera», las decisiones que deban garantizarla «han de adoptarse con carácter

31 Vide. STC 134/2011, de 20 de julio de 2011, FJ. 5.

32 Vide. SSTC 63/1986, de 21 de mayo, 201/1988, de 27 de octubre de 1988, y 96/1990, de 24 de mayo de 1990.

${ }^{33}$ Vide. STC 134/2011, de 20 de julio de 2011, FJ. 5, Ob. Cit.

${ }_{34}$ Ibíd.

${ }^{35}$ Vide. STC 134/2011, de 20 de julio de 2011, FJ. 8.a).

${ }^{36}$ Ibíd. 
general y de forma homogénea para todo el sistema y, en consecuencia por el Estado y en el ámbito estatal de actuación, no siendo posibles decisiones unilaterales que ... tendrían repercusiones en el conjunto ... y condicionarían las decisiones de otras Administraciones Autonómicas y de la propia Administración del Estado» ${ }^{37}$.

En la misma sentencia fundamenta el Tribunal Constitucional en el art. 149.1.11.a) y 13.b) la necesaria autorización del Estado a las Comunidades Autónomas para realizar operaciones de endeudamiento, y recuerda que el art. 14.4 LOFCA exige la necesidad de coordinar las operaciones de crédito de las Comunidades Autónomas con la política de endeudamiento del Estado en el seno del Consejo de Política Fiscal y Financiera. A mayor abundamiento, precisa que el establecimiento de un control sobre los presupuestos de las Comunidades Autónomas no menoscaba su autonomía financiera ya que no se trata de un control genérico sino derivado de una competencia concreta, en este caso derivado del artículo art. 149.1.13.a) CE. Por este motivo, considera que tampoco vulnera la autonomía financiera de las Comunidades Autónomas el examen por el Consejo de Política Fiscal y Financiera de las Comunidades Autónomas, órgano competente en relación con la aplicación efectiva del objetivo de estabilidad presupuestaria, del plan económico-financiero elaborado por éstas.

La jurisprudencia reafirmada y matizada por la presente sentencia del TC recalca la posición superior que ocupa el Estado respecto de las Comunidades Autónomas en materia financiera, lo que reduce el marco de sus posibilidades de acción máxime cuando se trata de fijar un techo de gasto que convierte a los derechos sociales, cuya concreción en gran parte le corresponde a los entes regionales, en plena y doblemente disponibles, en primer lugar por el legislador estatal, cuya voluntad viene determinada en parte por los compromisos europeos, y en segundo lugar por la voluntad de los parlamentos regionales.

\section{NOTAS FINALES}

En su concepción inicial, los derechos sociales se presentan en oposición a los derechos de libertad. Éstos han sido considerados desde el primer momento como verdaderos derechos ${ }^{38}$, mientras que aquellos se caracteriza-

37 Vid. STC 134/2011, de 20 de julio de 2011, FJ. 8.d) con remisión a la STC 31/2010, de 28 de junio de 2010, FJ. 13.

38 «Il faut donc rappeler qu'il existe deux catégories de droits de l'homme et seulement deux : les vrais et les faux. Les vrais droits de Lhomme sont effectivement ceux qui ont été proclamés, i.e. les droits que possède chaque individu, qu'il peut opposer au Pouvoir et que les gouvernants ont pour mission, et pour unique mission, de faire respecter. La liste des droits se ramène essentiellement à la trilogie lockéenne incluse dans le concept de propriety: la vie, la liberté et la propriété. Les faux droits de l'homme, ce sont des droits qui ne sont plus proclamés comme faisant partie de la nature éternelle de l'homme, mais des droits inventés de toutes pièces. Il ne s'agit plus alors de s'opposer à 
ban con una cierta vulnerabilidad normativa. Su concepción actual tiene una clara expresión en las palabras de García Pelayo cuando afirma que el Estado social niega la posibilidad de actualizar la libertad si su establecimiento y garantías formales no se acompañan de unas condiciones existenciales mínimas del individuo que permitan su ejercicio real ${ }^{39}$.

Aceptada esta afirmación, se hace preciso pleitear por un marco autonómico, estatal o europeo garante del estatus de ciudadanos y no sólo del individuo consumidor ${ }^{40}$. Eso es garantizar tanto la libertad como sus condiciones materiales de realización, lo que, en definitiva, propiciaría la construcción de una marco social y democrático, ya que «no se puede ni se debe ignorar que, cuando las normas que se generan extramuros del Estado, esto es, en los ámbitos regidos por la lex mercatoria propia de la mundialización económica, entran en colisión con las normas producidas democráticamente en los ámbitos del Estado, la tensión entre economía y política, entre razón económica, queda automáticamente transformada, se quiera o no, en la pavorosa confrontación entre democracia y antidemocracia, entre despotismo y libertad $»^{41}$.

l'intervention de l'Etat au sens large, mais de recourir à lui pour les mettre en auvre; il ne s'agit plus de droits-libertés, mais de droits-créances. L'État aurait le devoir, idéalement l'obligation, de tout mettre en ouvre pour assurer à chaque individu ou à chaque groupe telle ou telle créance : il ne n'agit plus de «droits de», mais de «droits à». Or, le mécanisme a été démontré par Frédéric Bastiat dès le milieu du XIX siècle : l'Etat ne peut rendre que ce qu'il a d'abord pris et, par surcroît, il n'en peut rendre qu'une partie. Il prend aux uns pour donner aux autres, il viole les vrais droits de l'homme pour tenter d'assurer les faux. Tenter, car les faux droits sont un puits sans fond, et pour deux raisons. D'abord, l'Etat est incapable de les fournir. Ensuite, les faux droits appellent les faux droits. A partir du moment où l'Etat tend à assurer un droit-créance, par définition arbitraire, il n'y a plus de limite à l'extension de l'Etat. Perpétuellement insatisfaits en raison de l'incapacité de l'Etat et du fait que certains individus ou certaines catégories socioprofessionnelles bénéficient de ses largesses, d'autres personnes ne manquent pas de venir clamer leur part de spoliation légale (...) Surtout, les faux droits de l'homme chassent les bons, à l'image de la fausse monnaie qui fait disparaître la bonne. En effet, on ne peut impunément mêler des droits contre l'Etat, qui permettent de sauvegarder la sphère de la société civile, et des droits réclamés à l'Etat, qui dès lors serait obligé d'empiéter sur cette sphère! (...) Bref, il s'agit d'une machine à faire exploser le Droit ». Jean-Philippe FELDMAN, "Le comité de réflexion sur le Préambule de la Constitution et la philosophie des droits de Lhomme », DALLOZ, 2009, págs. 1036-ss.

${ }^{39}$ Cfr. García Pelayo, M., «El Estado social y sus implicaciones» en Las transformaciones del estado contemporáneo, Alianza Universidad, Madrid, 1977, $3^{\text {a }}$ Ed. 1982, corregida y aumentada, págs. 13 al 26.

${ }_{40}$ Obsérvese que las últimas reformas operadas en la sanidad y la educación convierten los derechos que los sostienen en mercancías que, a corto o medio plazo, podría entrar en el ámbito de la competencia mercantil. Para más información, Véase: TAJAduRA TEJADA, J., «Los derechos sociales en el contexto de la globalización», en Teoría y Derecho. Los derechos sociales en tiempos de crisis, 2011, págs. 147-162.

${ }^{41}$ De Vega, P., Prólogo a Dromi San Martino, Laura: Derecho Constitucional de la Integración, Marcial Pons/Facultad de Derecho de la Universidad Complutense/Editorial 
Ello reclama, como tarea perentoria, culminar el proceso de legitimación democrática del poder en todos estos ámbitos, y garantizar que el poder político que se instale tenga la capacidad suficiente para ejercer los atributos de la soberanía que le han sido parcialmente arrebatados por los poderes privados ademocráticos que hoy por hoy subordinan gran parte de las decisiones que se toman al servicio de sus propios intereses. Intereses que merman, entre otros, la efectividad del principio básico del Estado de derecho cual es el de la separación de poderes tanto a nivel horizontal como vertical. Recuérdese que en España «las Comunidades Autónomas son parte del Estado, de ahí que lo que afecte al Estado debido a la integración comunitaria y a la mundialización les afecte también directa o indirectamente» ${ }^{42}$.

Proceso, bien llevado a cabo, permitirá sin lugar a dudas democratizar las relaciones económicas que trascienden las fronteras del Estado en cuyo seno se despliegan y hará que éstas, en el marco de un Estado de social de derecho, estén orientadas al bienestar de los individuos y no al beneficio mercantilista de la globalización. En suma, volver a lo que NAMoí KLEN denominó como «capitalismo decente». De lo contrario estaríamos favoreciendo la reversión de avances incontestables y la deconstrucción de consensos diligentemente forjados tanto en lo referido a la descentralización territorial de España como en lo tocante a la esencia social y democrática del Estado español que el poder constituyente logró establecer en 1978. Ésta comulga plenamente con la constatación de RUdolf SMEN de que la legitimidad del Parlamento no se evalúa en función de la realización de un ideal deliberativo sino por su capacidad de integración de los individuos en la comunidad política. La parte dogmática de la Constitución se concibe no sólo desde un punto de vista normativo sino desde una óptica axiológica que sirve principalmente la nueva función atribuida a la norma fundamental, a saber la de permitir la integración de todos los ciudadanos y de los grupos sociales en su seno.

RESUMEN: Este artículo repasa de modo genérico los elementos jurídicos que contribuyen a desvirtuar la potencialidad social del Estado español a través, principalmente, de la limitación del alcance prestacional del bloque competencial de las Comunidades Autónomas, destacándose que es el Estado el internacionalmente responsable por el incumplimiento de dichas prestaciones.

Palabras ClaVE: Estado de las autonomías, crisis económica, medidas de austeridad, Estado social.

TITLE: The «State of factual suspension» of the Welfare Autonomic State.

Ciudad Argentina, Madrid/Buenos Aires, 2000, pág. 21.

${ }^{42}$ Cfr. Pérez Calvo, A., «Estado autonómico, Unión Europea y mundialización», pág. 8, en http://www.falternativas.org/laboratorio/documentos/documentos-de-trabajo/ estado-autonomico-union-europea-y-mundializacion, última consulta el 07 de diciembre de 2012, Ob. Cit. 
ABSTRACT: This article reviews the legal elements that contribute to undermine the Welfare potential of the Spanish state through mainly limiting the scope of the social powers of the Autonomous Communities, stressing that it is the State internationally responsible for the failure of such benefits.

KEYWORDS: State of the Autonomies, economic crisis, austerity measures, Welfare State.

Recibido: 27.03.2013

Aceptado: 02.09.2013 